\title{
A Practical Circuit Model of High Frequency Transformers in
}

\section{Power Electronic Systems}

\author{
HaiYan $\mathrm{Lu}^{1}$, Jian Guo Zhu², YouGuang Guo ${ }^{2}$, and S.Y.R. Hui ${ }^{3}$
}

${ }^{1}$ Faculty of Information Technology, University of Technology, Sydney, P.O. Box 123, Broadway, NSW 2007, Australia

${ }^{2}$ Faculty of Engineering, University of Technology, Sydney, P.O. Box 123, Broadway, NSW 2007, Australia

${ }^{3}$ Department of Electronic Engineering, City University of Hong Kong, Tat Chee Avenue, Hong Kong, China

\begin{abstract}
This paper presents a practical circuit model of high frequency transformers in power electronic systems. All types of core losses, i.e., the hysteresis, classical eddy current and anomalous losses, are included in the model, and the thermal effect on magnetic hysteresis, the skin effect of eddy currents in magnetic cores, and the effect of stray capacitances are also considered. This model can therefore accurately predict the performance and core losses of transformers used in high frequency switching circuits. The practical methods for determining the circuit parameters are developed and presented in the paper, providing crucial benefit for practical applications. The developed model has been applied to simulate the performance of a $500 \mathrm{~W}$ transformer in a full bridge inverter operated with square waveform voltage excitation of $25 \mathrm{kHz}$. The simulations are validated by the experimental results.
\end{abstract}

Keywords-High frequency transformer, power electronic system, practical circuit model, core losses, thermal effect, stray capacitance, magnetic hysteresis, simulation. 


\begin{tabular}{|c|c|}
\hline Symbol and acronym & Definition \\
\hline$B(\mathrm{~T})$ & Magnetic flux density \\
\hline$C_{o}(\mathrm{~F})$ & Equivalent self-capacitance \\
\hline$C_{p s o}(\mathrm{~F})$ & Equivalent mutual capacitance between primary and secondary windings \\
\hline$f(\mathrm{~Hz})$ & Excitation frequency \\
\hline$\Phi(\mathrm{Wb})$ & Magnetic flux \\
\hline$H(\mathrm{~A} / \mathrm{m})$ & Magnetic field strength \\
\hline HFHPD & High frequency high power density \\
\hline$i(\mathrm{~A})$ & Current \\
\hline$L_{d l}(\mathrm{H})$ & Differential leakage inductance \\
\hline$\mu_{0}(\mathrm{Tm} / \mathrm{A})$ & Magnetic permeability of vacuum \\
\hline$\mu_{r}$ & Relative magnetic permeability \\
\hline$N$ & Number of turns of winding \\
\hline$\omega(\mathrm{rad} / \mathrm{s})$ & Angular frequency \\
\hline$P(\mathrm{~W})$ & Power loss \\
\hline$p$ & Subscript: primary side of transformer \\
\hline$R(\Omega)$ & Resistance \\
\hline$s$ & Subscript: secondary side of transformer \\
\hline$\sigma\left(\Omega^{-1} \mathrm{~m}^{-1}\right)$ & Electrical conductivity \\
\hline TLM & Transmission line model \\
\hline$V(\mathrm{~V})$ & Voltage \\
\hline
\end{tabular}




\section{INTRODUCTION}

With the rapid development of power electronic technologies, the transformers used in the power electronic systems are operated at higher and higher frequencies to increase the power density, resulting in smaller physical size and weight (Van Wyk, 1999). As the operating frequency increases, the modeling of transformers becomes a difficult task, because a number of factors, which have been neglected previously, must be taken into account. These factors, such as the thermal effect on magnetic hysteresis of magnetic core materials, skin effects in magnetic cores, core losses including the anomalous loss, and stray capacitances, have significant influence on the performance of transformers in high frequency operations. It would be very useful for design engineers to have a simple but accurate transformer model taking all these factors into consideration. The practical model should be simple to use or easy to formulate based on the data supplied from the manufacturers and/or obtained by simple measurements, and able to predict the performance with a satisfactory accuracy.

In modern power electronic systems, soft ferrites are commonly used as the core material of electromagnetic devices such as inductors and transformers for high frequency and high power density applications because of their advantageous characteristics of high magnetic permeability and low eddy current loss at high excitation frequencies. The magnetic properties of soft ferrites, however, are sensitive to temperature (SIEMENS, 1990; Philips, 1996). This causes difficulties in performance prediction and design of electromagnetic devices. Based on sophisticated experimental study, the authors of this paper previously developed two models for considering the thermal effect on hysteresis of soft ferrites based on a careful experimental study on magnetic hysteresis loops of various soft ferrite samples from different manufacturers (Lu, 1999; Zhu, 1997). The normal scalar Preisach model, which has been proven effective and convenient 
for modeling the magnetization process in magnetic cores (Hui, 1994; Zhu, 1996; Hui, 1996), has been modified to incorporate the thermal effect on magnetic hysteresis. With the modified Preisach model, it is possible to predict accurately the instantaneous B-H operating point in an excited magnetic core at any given temperature within the normal working temperature range.

At high frequencies, the effect of stray capacitances becomes significant and should be taken into account in the modeling and simulation of high frequency transformers (Blache, 1994; Laveuve, 1991; Baccigalupi, 1993; Poulichet, 2003; Massarini, 1996; Mao, 2002; Grandi, 1996). A study on experimental determination of stray capacitance of high frequency transformers by the authors (Lu, 2003) has revealed that the overall effect of stray capacitances in a two-winding transformer can be modeled properly by a $\pi$-shaped network of three capacitances or approximately as a single lumped capacitance across the primary terminals, and the capacitances can be easily determined by using the proposed experimental techniques.

This paper presents a practical but accurate dynamic circuit model of high frequency high power density (HFHPD) transformers, which takes all the factors mentioned above into account. Section 2 illustrates the circuit model of transformers as well as the discrete circuit equations obtained by using the transmission line model (TLM) based discrete technique (Hui, 1992; Zhong, 1993). Section 3 introduces the determination of circuit parameters in the model, and Section 4 shows the experimental verification of the transformer model by using a $500 \mathrm{~W}$ transformer supplied by a $25 \mathrm{kHz}$ square waveform voltage in a full bridge inverter. Section 5 demonstrates the effects of magnetic hysteresis and stray capacitances. Finally, major conclusions and contributions of the paper are summarized in Section 6. 


\section{A PRACTICAL CIRCUIT MODEL OF HIGH FREQUENCY TRANSFORMERS}

A two-winding high frequency transformer including the stray capacitance effect is illustrated in Fig. 1, where $R$ is the winding resistance, $V$ the terminal voltage, $i$ the winding current, $N$ the number of turns of winding, the subscripts $p$ and $s$ denote the primary and secondary sides, $C_{p o}$ and $C_{s o}$ are the equivalent selfcapacitances of the primary and secondary windings due to the turn-to-turn, layer-to-layer and turn-to-core electrical couplings, respectively, and $C_{p s o}$ is the equivalent mutual capacitance due to the electrical coupling between the two windings.

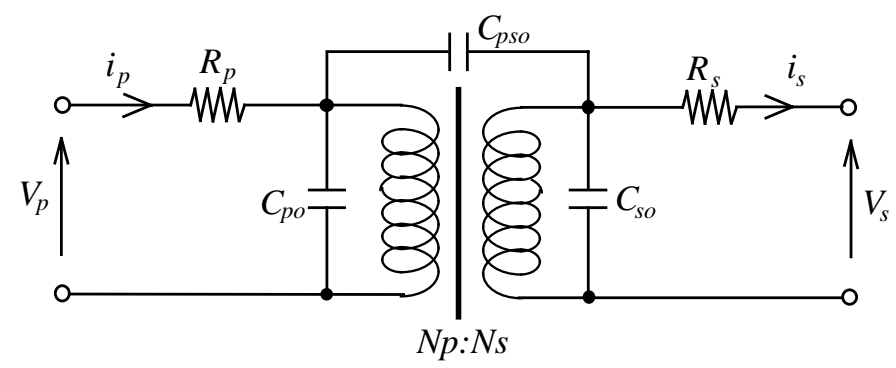

Fig. 1. A two-winding high frequency transformer

Incorporating the $n$-stage ladder network model for magnetic cores with eddy currents (Zhu, 1996; Hui, 1996), and referring all the parameters to the primary side (normalized to one turn for simplicity of analysis), we obtain an equivalent electric circuit shown in Fig. 2, where $L_{d l p}$ and $L_{d l s}$ are the differential leakage inductances of the primary and secondary windings, respectively, $C_{p}, C_{s}$ and $C_{p s}$ the equivalent capacitances of $C_{p o}$, and $C_{s o}$ and $C_{p s o}$ referred to the normalized primary side by

$$
\begin{aligned}
& C_{p}=C_{p o}+(1-k) C_{p s o} \\
& C_{s}=k^{2} C_{s o}+k(k-1) C_{p s o} \\
& C_{p s}=k C_{p s o}
\end{aligned}
$$

and $\quad k=N_{s} / N_{p}$. 


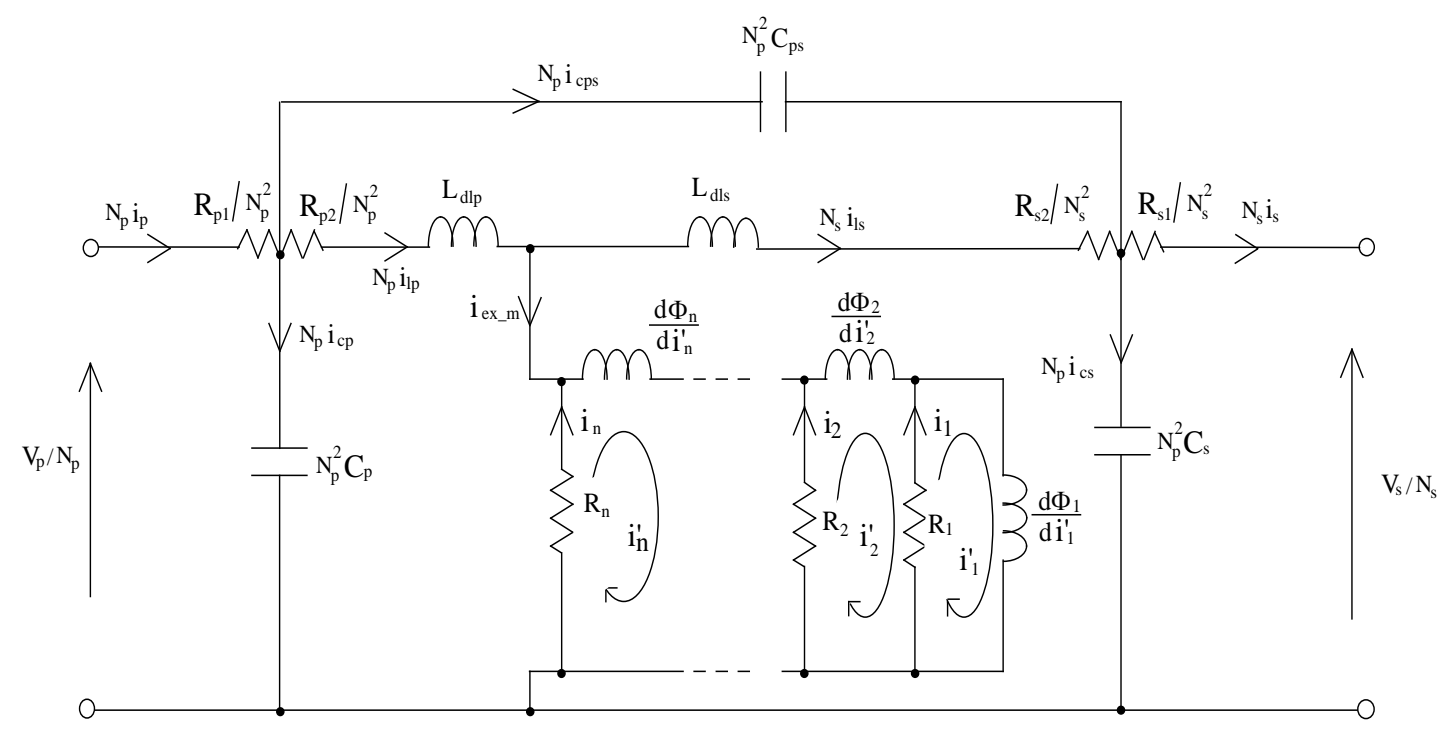

Fig. 2. Equivalent electric circuit model of a high frequency transformer (referred to primary side normalized to one turn)

In the $n$-stage ladder network, each $R L$ unit represents an assumed equivalent eddy current path (to be detailed in Section 3), and $i_{k}, R_{k}$ and $\Phi_{k}$ indicate the lumped eddy current, equivalent resistance for the eddy current loss in the path, and the magnetic flux linking the $k$-th equivalent eddy current path, respectively, $i^{\prime}{ }_{k}$ is the mesh current for the $k$-th stage, and $d \Phi_{k} / d i^{\prime}{ }_{k}$ (i.e. $\left.L_{d k}\right)$ gives the differential inductance $(k=1,2, \ldots, n)$.

In terms of the mesh currents, the circuit equations of the ladder network can be written as:

$$
\begin{aligned}
& R_{1} i_{1}+L_{d 1} \frac{d i_{1}^{\prime}}{d t}=0 \\
& R_{2} i_{2}+L_{d 1} \frac{d i_{1}^{\prime}}{d t}+L_{d 2} \frac{d i_{2}^{\prime}}{d t}=0 \\
& \bullet \bullet \\
& R_{n} i_{n}+L_{d 1} \frac{d i_{1}^{\prime}}{d t}+L_{d 2} \frac{d i_{2}^{\prime}}{d t}+\bullet \bullet+L_{d n} \frac{d i_{n}^{\prime}}{d t}=0 \\
& \frac{V_{p}}{N_{p}}=i_{p} \frac{R_{p 1}}{N_{p}}+\frac{1}{N_{p} C_{p}} \int i_{c p} d t
\end{aligned}
$$




$$
\begin{aligned}
& \frac{V_{p}}{N_{p}}-R_{n} i_{n}=i_{p} \frac{R_{p 1}}{N_{p}}+i_{L p} \frac{R_{p 2}}{N_{p}^{2}}+L_{d L p} \frac{d i_{L p}}{d t} \\
& L_{d L s} \frac{d i_{L s}}{d t}+i_{L s} \frac{R_{s 2}}{N_{s}^{2}}+i_{s} \frac{R_{s 1}}{N_{s}}+\frac{V_{s}}{N_{s}}+R_{n} i_{n}=0 \\
& \frac{1}{N_{p} C_{p s}} \int i_{c p s} d t=i_{L p} \frac{R_{p 2}}{N_{p}^{2}}+L_{d L p} \frac{d i_{L p}}{d t}+L_{d L s} \frac{d i_{L s}}{d t}+i_{L s} \frac{R_{s 2}}{N_{s}^{2}} \\
& i_{n}^{\prime}+i_{L s}=i_{L p}+i_{n} \\
& N_{p} i_{p}=i_{L p}+N_{p} i_{c p}+N_{p} i_{c p s} \\
& N_{p} i_{c p s}+i_{L s}=N_{s} i_{s}+N_{p} i_{c s}
\end{aligned}
$$

and

$$
i_{k}^{\prime}=i_{k}+i_{k+1}^{\prime}, \quad(k=1,2, \ldots, n-1)
$$

where $R_{p}$ and $R_{s}$ have been split into two parts as $R_{p 1}=R_{p 2}=0.5 R_{p}$ and $R_{s 1}=R_{s 2}=0.5 R_{s}$, respectively, for avoiding pure capacitor-inductor branches (Grossner, 1967).

By using the TLM-based discrete technique (Hui, 1992; Zhong, 1993), the differential and integral terms in the above equations can be expressed as

$$
\frac{d i_{L}}{d t}=Z_{u} i_{L}+2 V_{u}^{i_{L}}
$$

and $\quad \int i_{c} d t=Z_{c} i_{c}+2 V_{c}^{i_{c}}$

where $Z_{u}=2 / T_{p}$ and $Z_{c}=T_{p} / 2$ are the characteristic impedances of the TLM stubs which represent an inductance of $1 \mathrm{H}$ and a capacitance of $1 \mathrm{~F}$, respectively, $T_{p}$ is the propagation time which is equivalent to the time step in numerical simulation, and $V_{u}^{i_{L}}$ and $V_{c}^{i_{c}}$ are the incident pulses used in the TLM technique. Equations (4)-(14) can then be re-written as a set of linear equations in terms of mesh currents. 
The leakage inductances in a high frequency transformer are small compared to the magnetization inductances in general. For example, a $500 \mathrm{~W}$ EE-core transformer $\left(N_{p}=10, N_{s}=8\right)$ operated under $25 \mathrm{kHz}$ square waveform excitation has a leakage inductance of $1.02 \mu \mathrm{H}$ for each winding (including the test leads) referred to the primary side while the magnetization inductance is about $1.2 \mathrm{mH}$. The voltage drop across the leakage inductance is insignificant and hence the overall effect of three stray capacitors can be simplified by an equivalent stray capacitor connected on the primary side as shown in Fig. 3. The single capacitance can be approximately related to the stray capacitances in Fig. 2, by

$$
C_{s t r} \approx C_{p}+C_{s}
$$

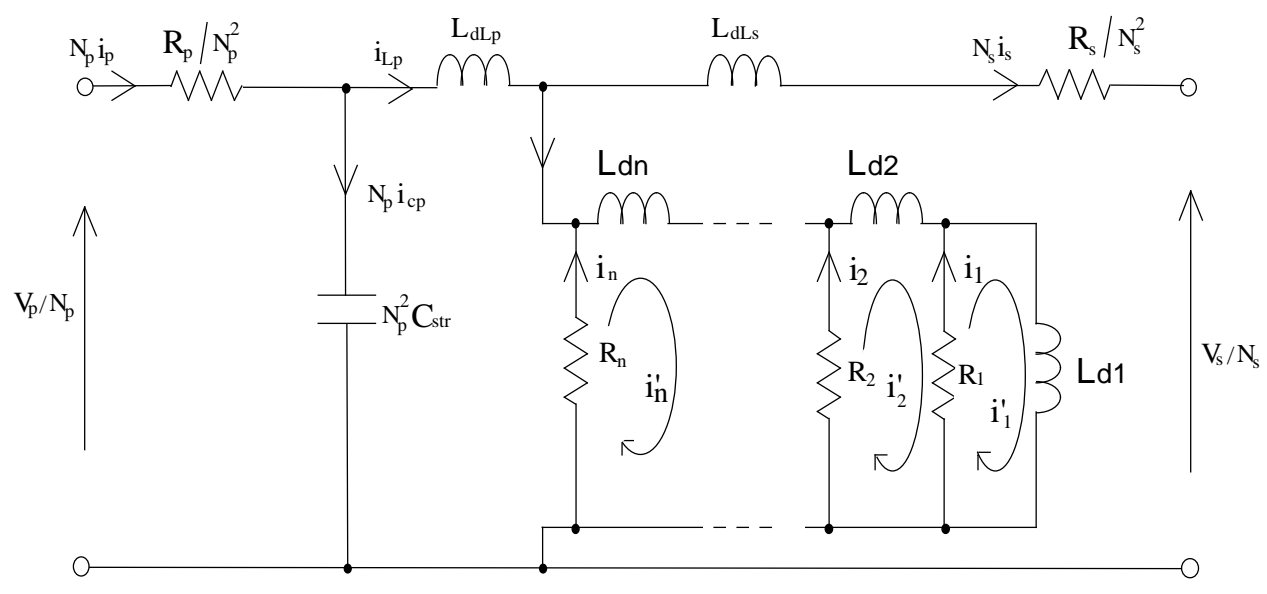

Fig. 3. Practical circuit model of high frequency transformer with single equivalent stray capacitance

\section{PARAMETER IDENTIFICATION METHOD}

\subsection{Equivalent eddy current paths}

Due to the skin effect generated by the eddy currents in the magnetic core at a high switching frequency, the distribution of magnetic flux density is not uniform over the cross section of the magnetic core. In order to account for the skin effect, the magnetic core should be subdivided into a number of small parts with specified properties (Zhu, 1996; Hui, 1996). Firstly, the magnetic core can be subdivided into several (say q) 
segments along the main magnetic flux paths such that each segment has a unique cross-sectional area. This can be done based on the physical dimensions of the magnetic core. Secondly, the cross section of each segment can be subdivided into a number of (say $n$ ) eddy current paths such that the distribution of magnetic flux density can be assumed to be uniform within each path. All segments should have the same number of eddy current paths. To determine the number of the paths, $n$, the maximum width of the paths, $w_{s}$, should be less or equal to the skin depth $\delta$ at the fundamental excitation frequency $f$ by

$$
w_{s} \leq \delta=\sqrt{\frac{2}{\omega \sigma \mu_{\mathrm{r}} \mu_{0}}}
$$

where $\omega=2 \pi f$ is the angular frequency of the excitation, $\sigma$ the electrical conductivity of the material, $\mu_{0}$ the magnetic permeability in free space, and $\mu_{r}$ the relative permeability of the core material. The $k$-th equivalent eddy current path of the entire magnetic core is assumed to be the combination of all the $k$-th eddy current paths in all the core segments and comply with the principle of magnetic flux continuity, $(k=$ $1,2, \ldots, n)$

\subsection{Equivalent eddy current loss resistance}

The assumed eddy current paths over the rectangular cross section of one segment of the EE core are shown in Fig. 4, in which all the eddy current paths have the same width. Since the eddy current density vector can be assumed one-dimensional at every point over the cross section, each eddy current path can be transferred into a pair of slices shown in Fig. 5. The length of each slice $\left(a_{k}\right)$, is the half of the mean length of the assumed eddy current path in Fig. 4 while the width $(\Delta y)$ keeps unchanged. The total core loss in the $k$-th $(k=1,2, \ldots n)$ pair of slices is equivalent to the one occurred in the corresponding eddy current path of Fig. 4. Therefore, based on the study on ring cores (Zhu, 1996; Hui, 1996), the total classical eddy current and anomalous loss in the $k$-th eddy current path of the EE core can be calculated by (Lu, 1998) 


$$
P_{e a k}=\sum_{i}^{q}\left(\frac{2 a_{i k} l_{i} \Delta y_{i}}{\sigma_{i}}\right) J_{i k}{ }^{2} r_{J i k} r_{C i k}
$$

where $l_{i}$ is the segment length along the direction of the main flux density $B_{z}, J_{i k}$ the eddy current density at $\mathrm{y}=\mathrm{y}_{\mathrm{k}}, r_{J i K}=\left[1+\left(1+J_{i(k-1)} / J_{i k}\right) J_{i(k-1)} / J_{i k}\right] / 3$ a factor considering the variation of current density in the $k$-th path, $r_{c i k}=1+C_{a} /\left(C_{e} \sqrt{\left|d B_{z} / d t\right|_{i k}}\right)$ a correction factor accounting for the anomalous loss in the $k$-th path of the $i$-th segment, and $C_{e}$ and $C_{a}$ are the eddy current and anomalous loss coefficients, respectively. $C_{a}$ and $C_{e}$ can be determined by the core loss separation procedure described in (Zhu, 1996; Hui, 1996).

In the equivalent circuit shown in Fig. 2 or 3 , the eddy current loss resistance $R_{k}(k=1,2, \ldots, n)$ accounts for the total eddy current loss in the $k$-th assumed eddy current path of all segments and can be calculated by

$$
R_{k}=\frac{V_{k}^{2}}{P_{e a k}}
$$

where $V_{k}$ is the voltage across the resistance $R_{k}$.

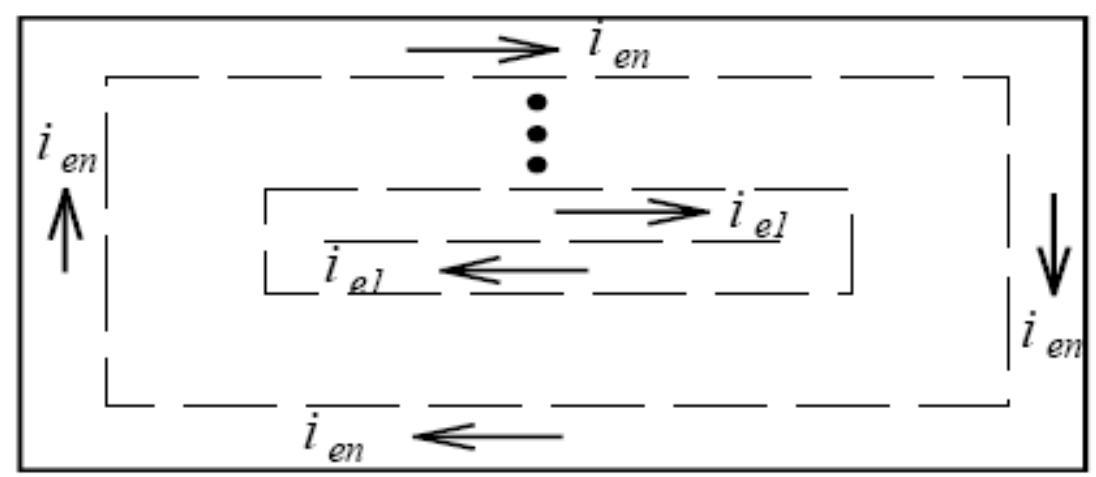

Fig. 4. Rectangular cross section with assumed eddy current paths 


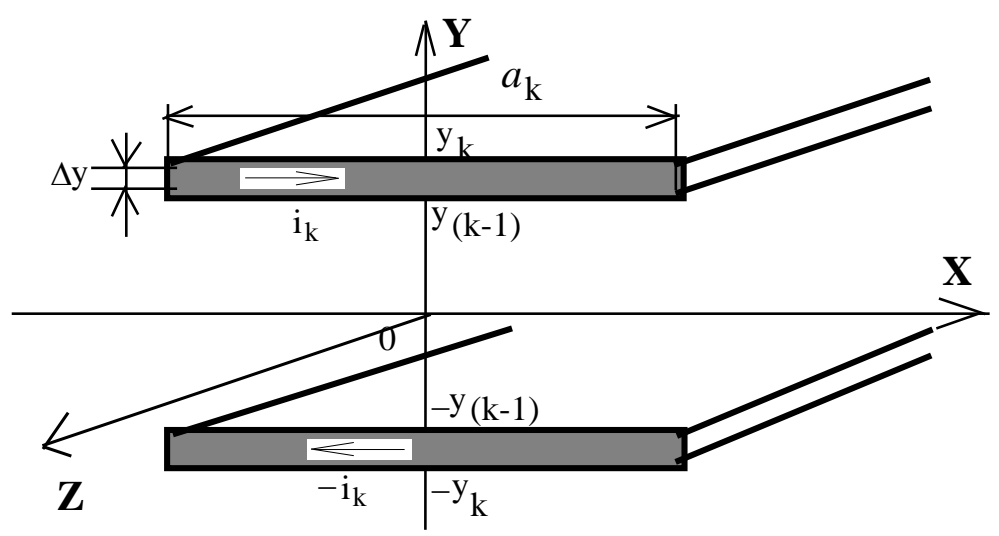

Fig. 5. Equivalent pair of slices of the $k$-th eddy current path in Fig. 4

\subsection{Equivalent differential inductances}

At a time instant, the mesh currents $i_{k}{ }^{\prime}(k=1,2, . ., n)$ can be obtained by solving simultaneously (4)-(14) or the equivalent linear equations deduced from these equations by the TLM technique ( $\mathrm{Lu}, 1998)$. The magnetic flux density and magnetic field strength in different eddy current paths of a segment are obtained by solving the non-magnetic circuit using the Newton-Raphson method. When the flux densities of two consecutive time steps are obtained, the differential inductance corresponding to the $k$-th path can be calculated by

$$
L_{d k}=\frac{d \Phi_{k}}{d i_{k}^{\prime}} \cong A_{k} \frac{B_{k(m)}-B_{(m-1)}}{i_{k(m)}^{\prime}-i_{k(m-1)}^{\prime}}
$$

where $A_{k}$ is the cross-sectional area of the $k$-th eddy current path in the segment with the excitation coil, $B_{k}$ the flux density, and subscripts $(m)$ and $(m-1)$ refer to the $m$-th and ( $m-1)$-th time steps, respectively.

\subsection{Lumped stray capacitances}

The lumped stray capacitances in the circuit shown in Fig. 2 can be determined by using the experimental techniques proposed in ( $\mathrm{Lu}, 2003)$. 


\section{Experimental Verification}

\subsection{Test transformer}

A $500 \mathrm{~W}$ EE soft ferrite (N27) core two-winding transformer provided by ex-EXCOM, Australia, was chosen as the test transformer. It was designed for a full bridge inverter in a telecommunication system and with $25 \mathrm{kHz}$ square waveform voltage excitation. The materials and parameters of the major components of the test transformer are listed in Table 1.

Table I

Parameters of a $500 \mathrm{~W} 25 \mathrm{kHz}$ EE core transformer

\begin{tabular}{|l|lc|}
\hline Core material & Soft ferrite N27 (Siemens) \\
\hline Winding material & Copper foil of 0.10 mm thickness \\
\hline \multirow{2}{*}{ Number of turns } & Primary winding: & 10 turns \\
& Secondary winding: & 8 turns \\
\hline Winding resistance & Primary winding: & $0.014 \Omega$ \\
(DC) & Secondary winding: & $0.012 \Omega$ \\
\hline Insulation material & NOMEX T410, thickness: $80 \mu \mathrm{m}$, and width: 44 \\
\hline
\end{tabular}

\subsection{Simulation and experimental verification}

Because of the very low conductivity of the soft ferrite used in the test transformer, the skin depth is quite large at $25 \mathrm{kHz}$, and a two stage ladder network would be sufficiently accurate for simulating the nonuniform eddy currents in the core. 


\subsubsection{No-load test with square wave primary voltage excitation}

Under the no-load condition or the secondary side open circuited, the waveforms of the primary current and the secondary voltage of the test transformer with respect to a $25 \mathrm{kHz}$ square wave primary voltage excitation were simulated by using the circuit models shown in Figs. 2 and 3, respectively, and compared with experimental measurement under the same conditions. The three lumped stray capacitances used in Fig. 2 are $C_{p}=2.65 \mathrm{nF}, C_{s}=0.82 \mathrm{nF}$, and $C_{p s}=0.17 \mathrm{nF}$ (referred to one turn), which were determined by the two-port network approach (Lu, 2003), and the single lumped stray capacitance in Fig.3 is $C_{\text {str }}=0.37 \mathrm{nF}$

(referred to one turn), which was determined by the step-response approach (Lu, 2003). The operational temperature is $62{ }^{\circ} \mathrm{C}$. The normal time step for the TLM based discrete solution was set as $39.06 \mathrm{~ns}$ (1024 step in one cycle) and the sub-time step was set as one tenth of the normal time step.

The predicted voltage and current waveforms and the flux against the excitation current loops obtained by using the two circuits are plotted against the experimental results in Figs. 6-7, respectively. It is shown that the simulated results, which are obtained by using both the three lumped stray capacitances and the single equivalent capacitance, agree substantially with the experimental results. The noticeable discrepancies around the beginning and the end of a switching period might be due to the error introduced by the interpolation.

Tables II and III tabulate the measured and calculated core losses under the no-load condition using the equivalent circuits in Figs. 2 and 3, respectively. The percentage errors of core loss prediction are less than 5\%, and the model with three stray capacitance appears to be slightly more accurate. 
Table II

Comparison of the calculated and measured core losses under no-load condition using the circuit in Fig. 2

\begin{tabular}{||c|c|c|c||}
\hline \hline Excitation Voltage & $\mathrm{P}_{\text {core }}$ (cal.) (W) & $\mathrm{P}_{\text {core }}($ exp.) $(\mathrm{W})$ & Error (\%) \\
\hline Square wave, 150V (25kHz) & 21.35 & 20.41 & 4.59 \\
\hline
\end{tabular}

Table III

Comparison of the calculated and measured core losses under no-load condition using the circuit in Fig. 3

\begin{tabular}{||c|c|c|c||}
\hline \hline Excitation Voltage & $\mathrm{P}_{\text {core }}($ cal.) $(\mathrm{W})$ & $\mathrm{P}_{\text {core }}($ exp.) $(\mathrm{W})$ & Error (\%) \\
\hline Square wave, 150V $(25 \mathrm{kHz})$ & 21.24 & 20.41 & 4.06 \\
\hline
\end{tabular}

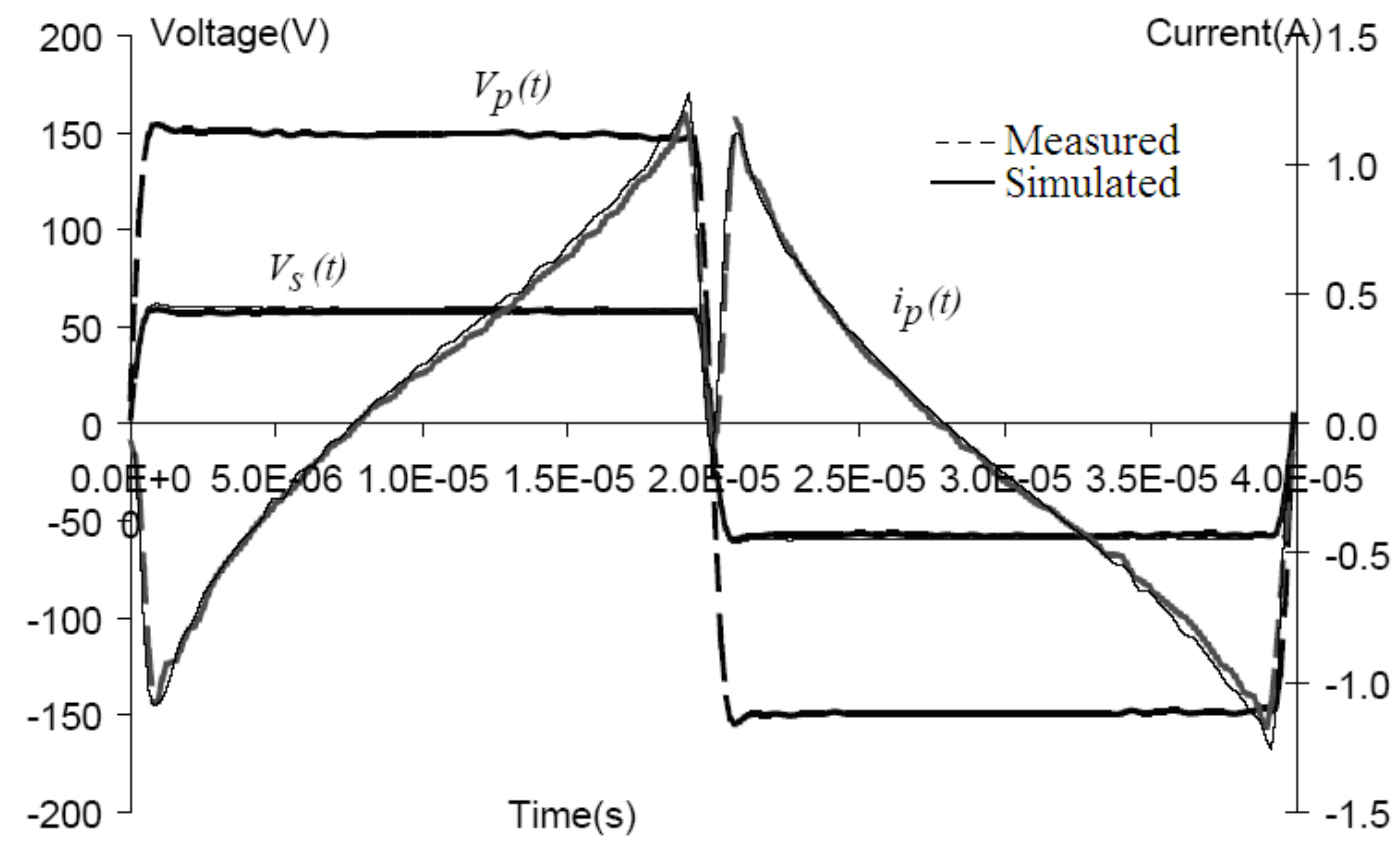

(a) 


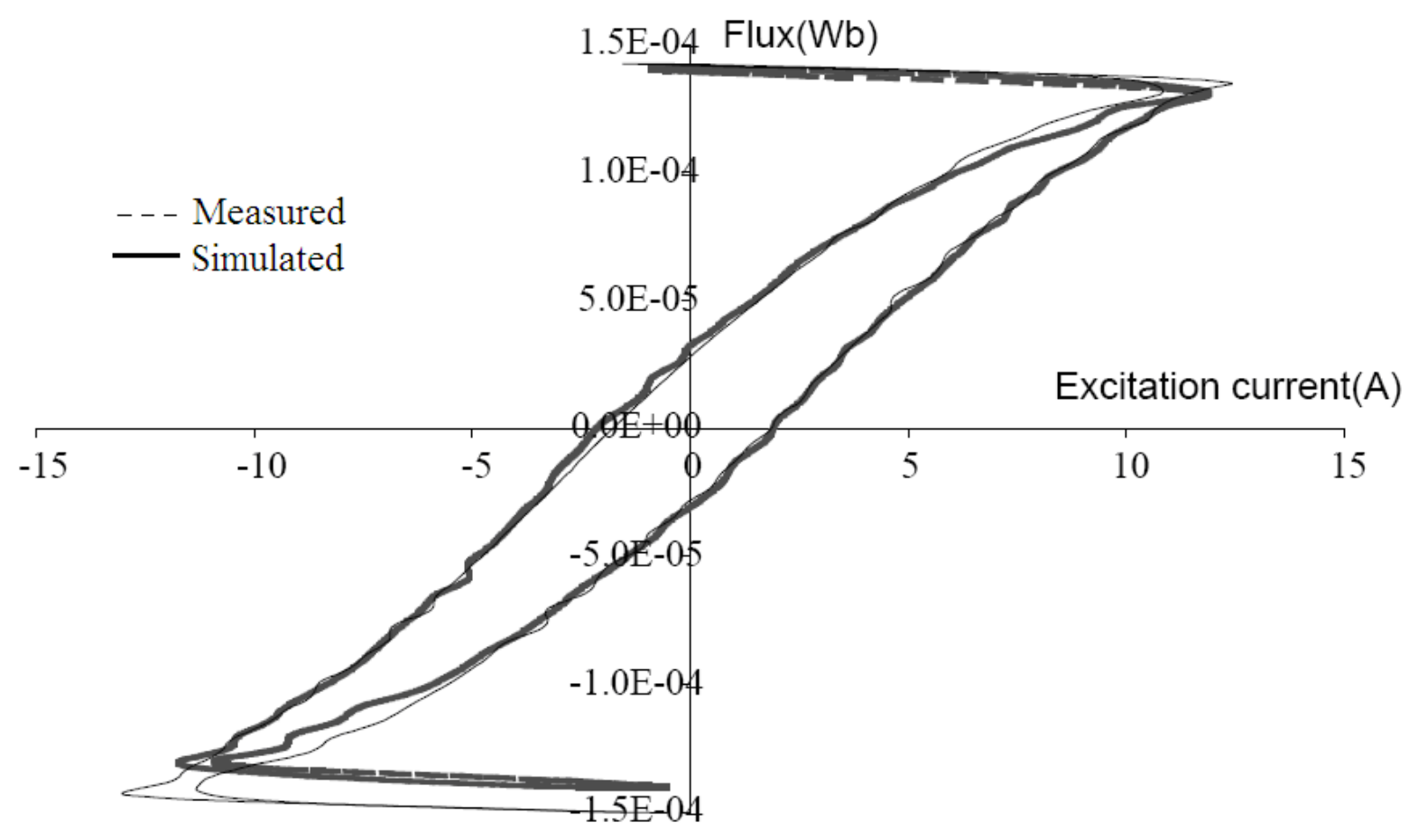

(b)

Fig. 6. Comparison of simulated and measured results at $25 \mathrm{kHz}$, no-load, using three stray capacitor model in Fig. 2 with $C_{p}=2.65$ $\mathrm{nF}, C_{s}=0.82 \mathrm{nF}$, and $C_{p s}=0.17 \mathrm{nF}$ : (a) primary current and secondary voltage, and (b) flux against excitation current

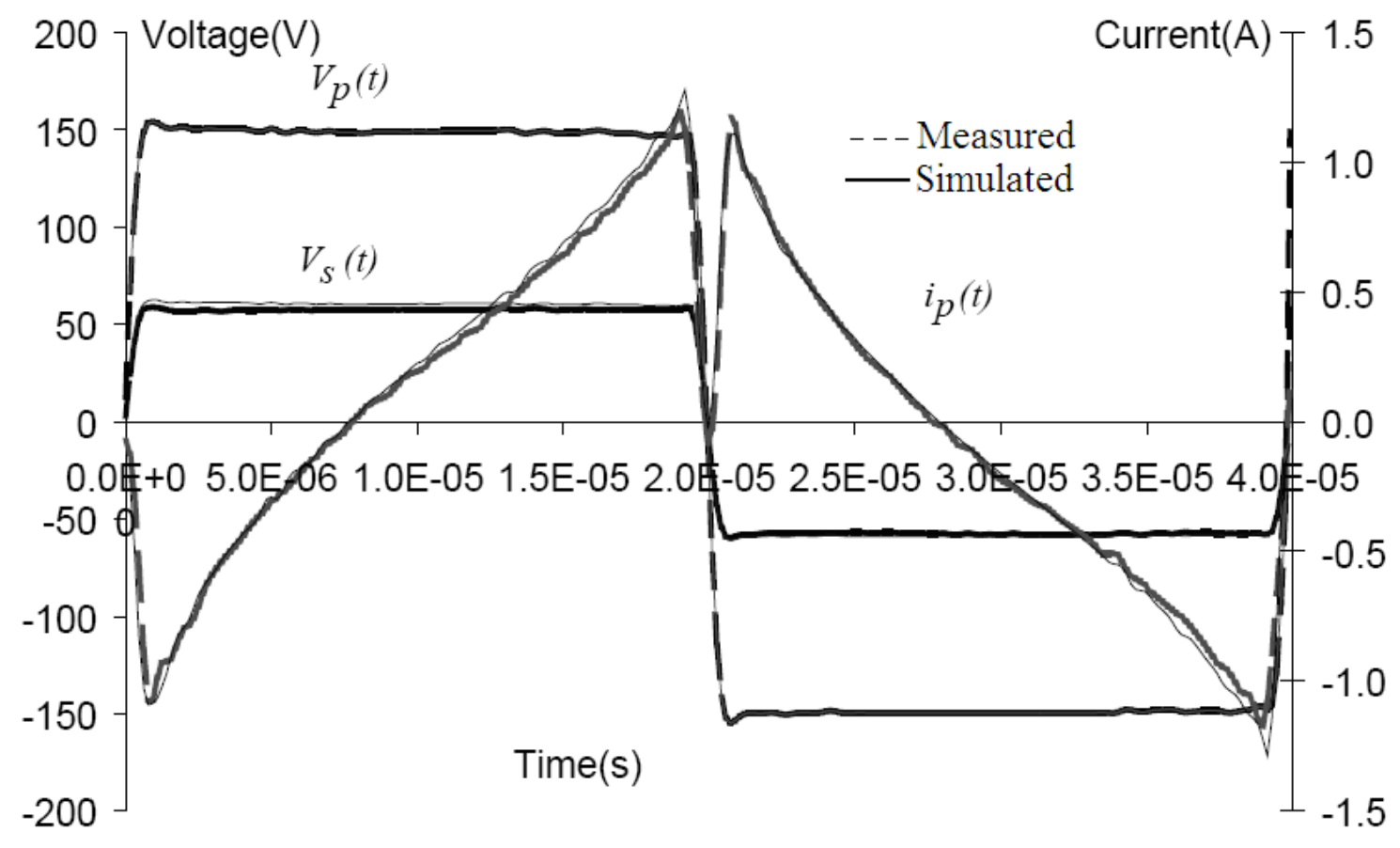

(a) 


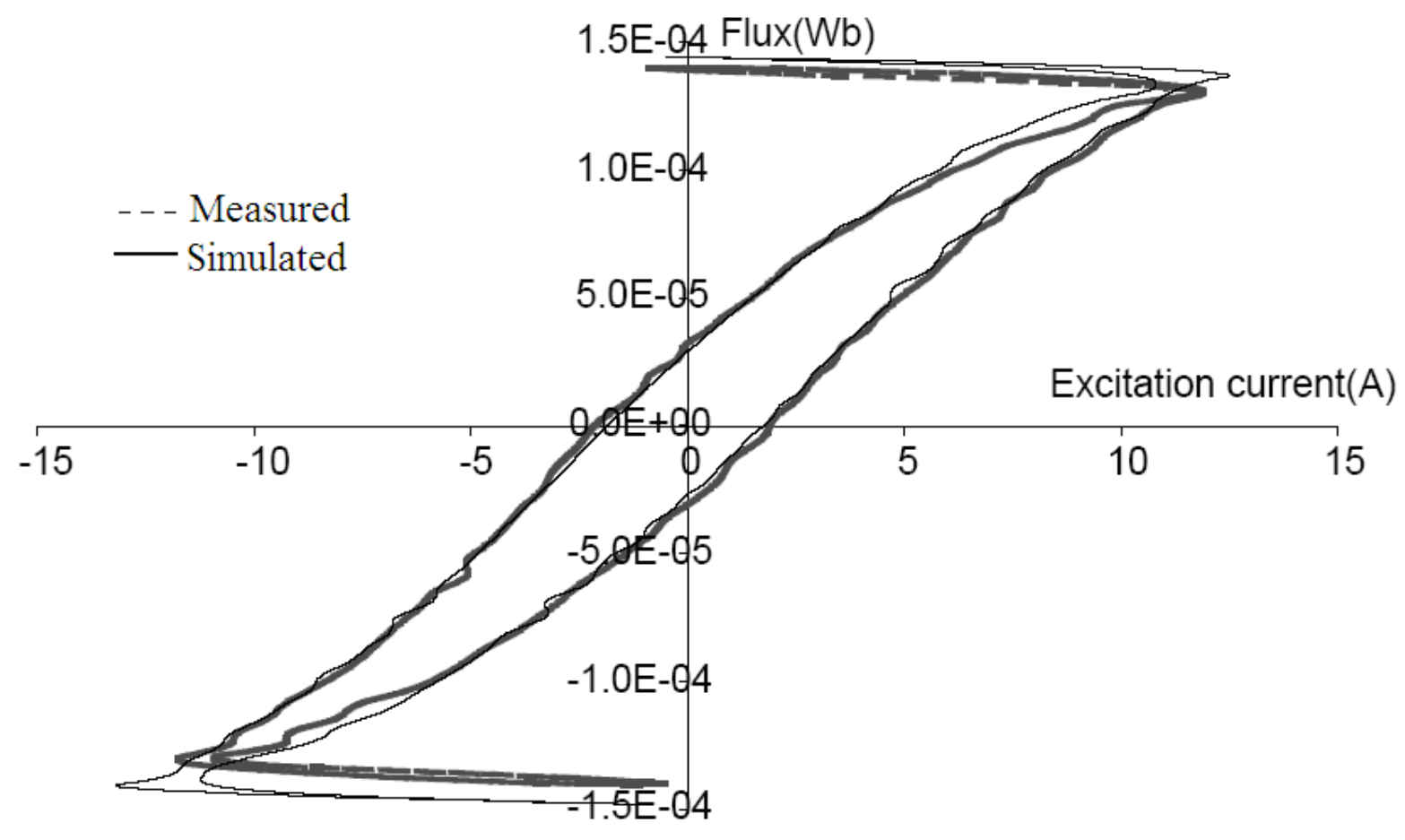

(b)

Fig. 7. Comparison of simulated and measured results at $25 \mathrm{kHz}$, no-load, using single stray capacitor model in Fig. 3 with $C_{\text {str }}=3.70 \mathrm{nF}$ : (a) primary current and secondary voltage, and (b) flux against excitation current

\subsubsection{Load tests with square wave primary voltage excitation}

The waveforms of the primary current and the secondary voltage and current of the test transformer under a 150 V 25 kHz square wave primary voltage excitation were simulated by using the circuit model in Fig. 3 with $C_{\text {str }}=0.37 \mathrm{nF}$, under two different loads $(R=10.52 \Omega, L=13.98 \mu \mathrm{H}$; and $R=4.96 \Omega, L=9.10 \mu \mathrm{H})$, with the operating temperatures of $70{ }^{\circ} \mathrm{C}$ and $81{ }^{\circ} \mathrm{C}$, respectively. The normal time step for the TLM based discrete solution was set as 39.06 ns and the sub-time step was set as one hundredth of the normal time step.

The voltage and current waveforms predicted by using the two circuit models are plotted against the experimental results in Figs. 8 and 9, respectively. It is shown that the simulated results, which are obtained 
by using both the three lumped stray capacitances and the single equivalent stray capacitance, agree substantially with the experimental results.

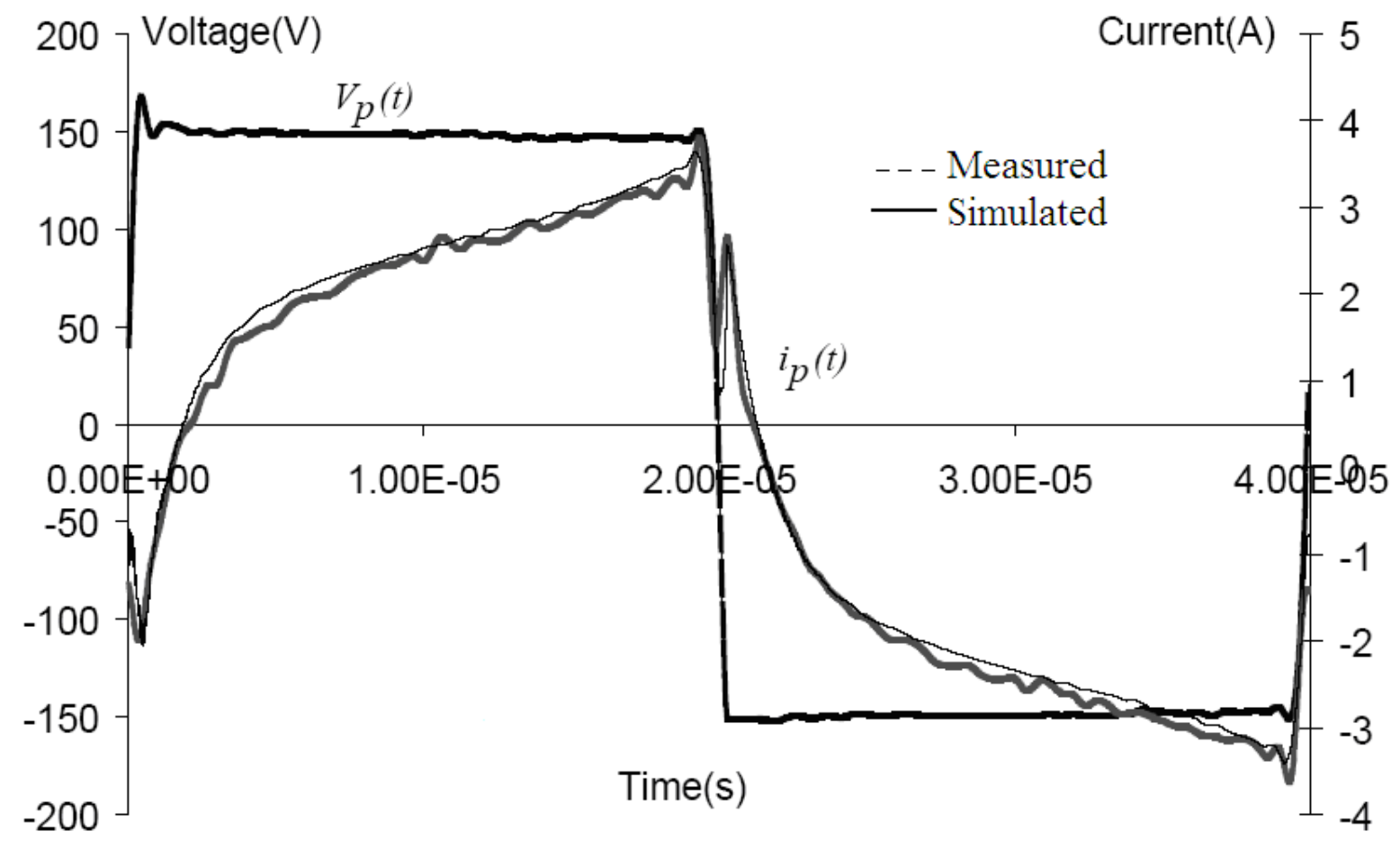

(a) 


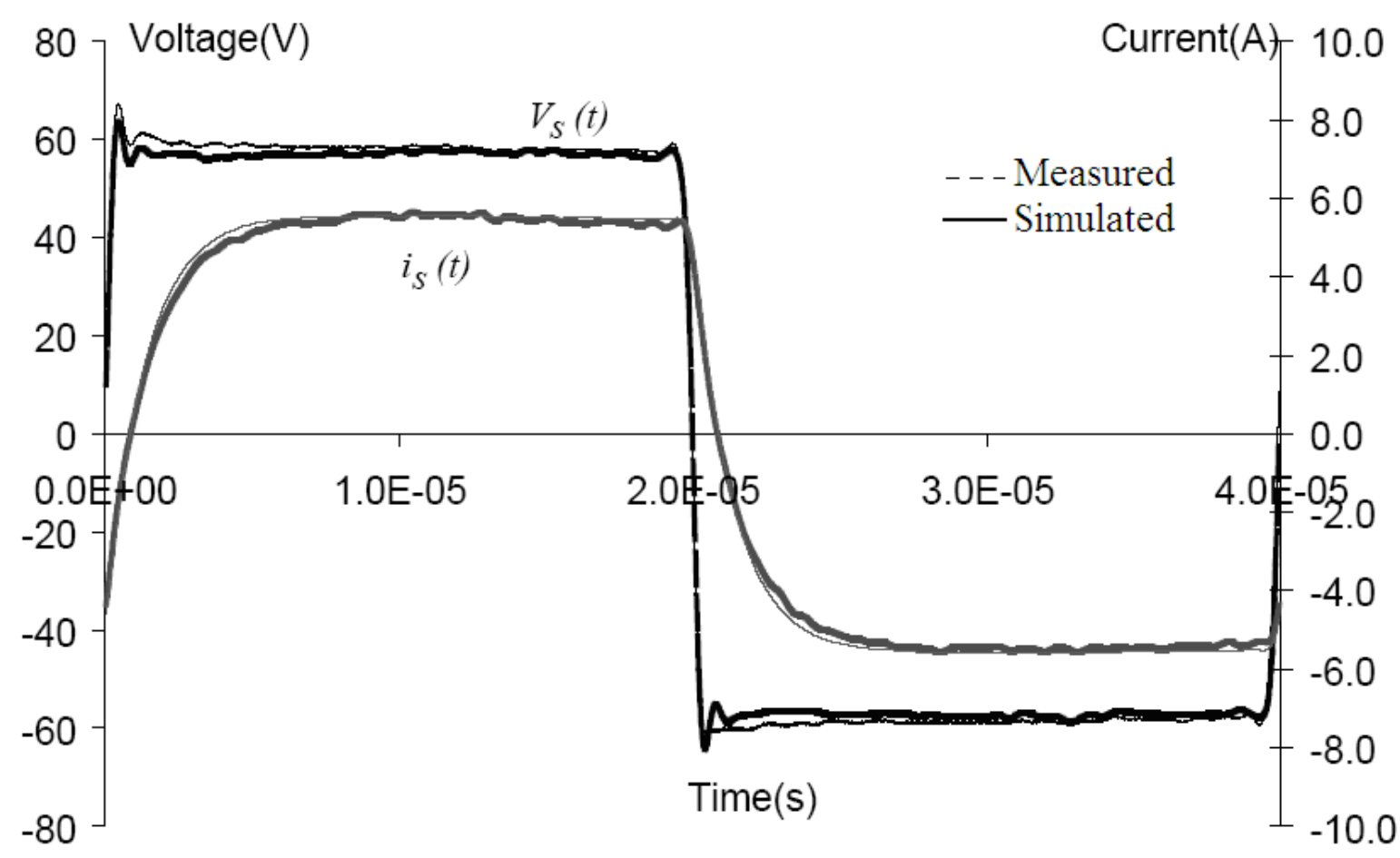

(b)

Fig. 8. Comparison of measured and simulated results by using single stray capacitor model in Fig. $3 \mathrm{with} C_{\mathrm{str}}=3.70 \mathrm{nF}$ under an inductive load of $R=10.52 \Omega$ and $L=13.98 \mu \mathrm{H}$ at $25 \mathrm{kHz}$ : (a) primary current, (b) secondary current and voltage

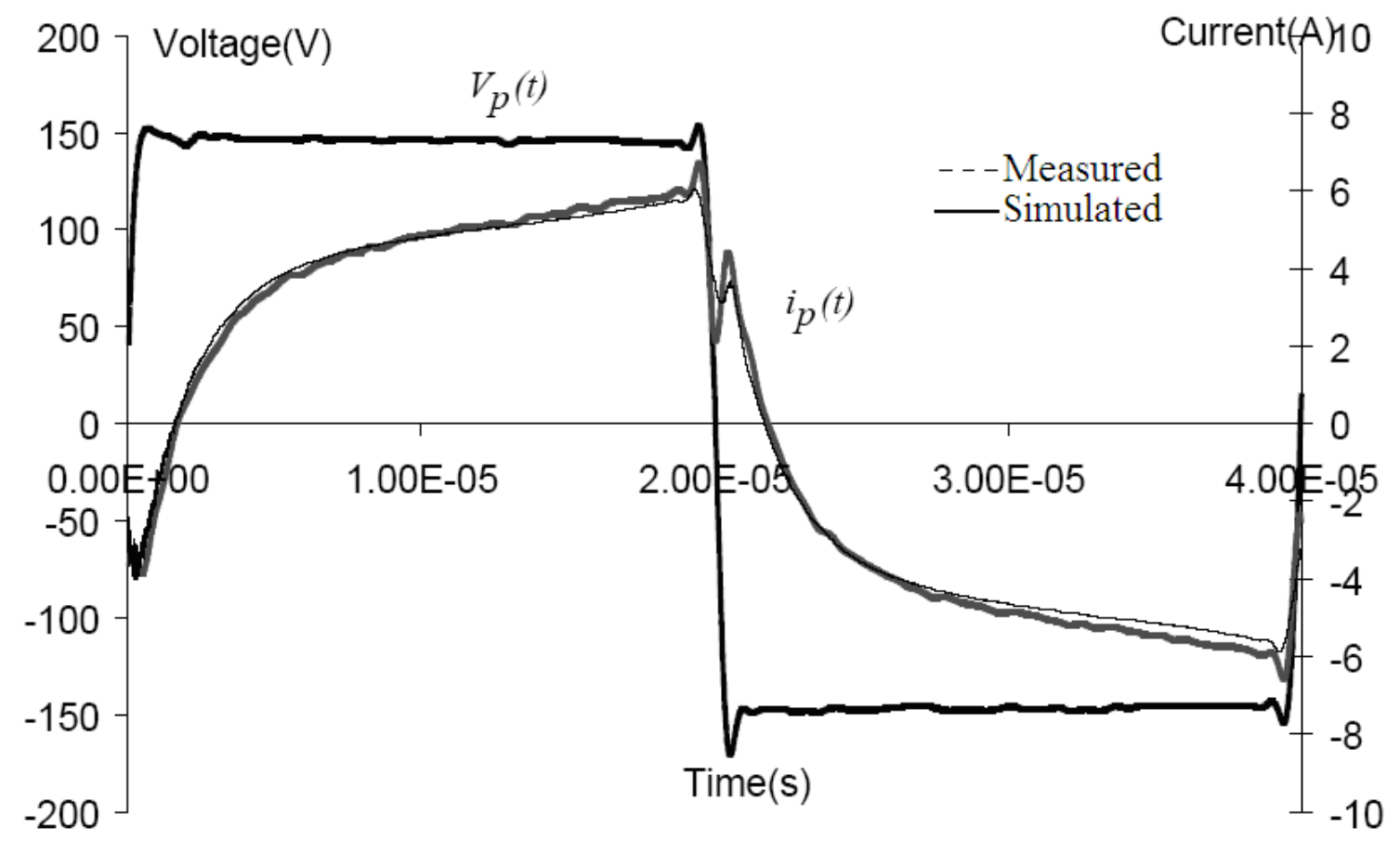

(a) 

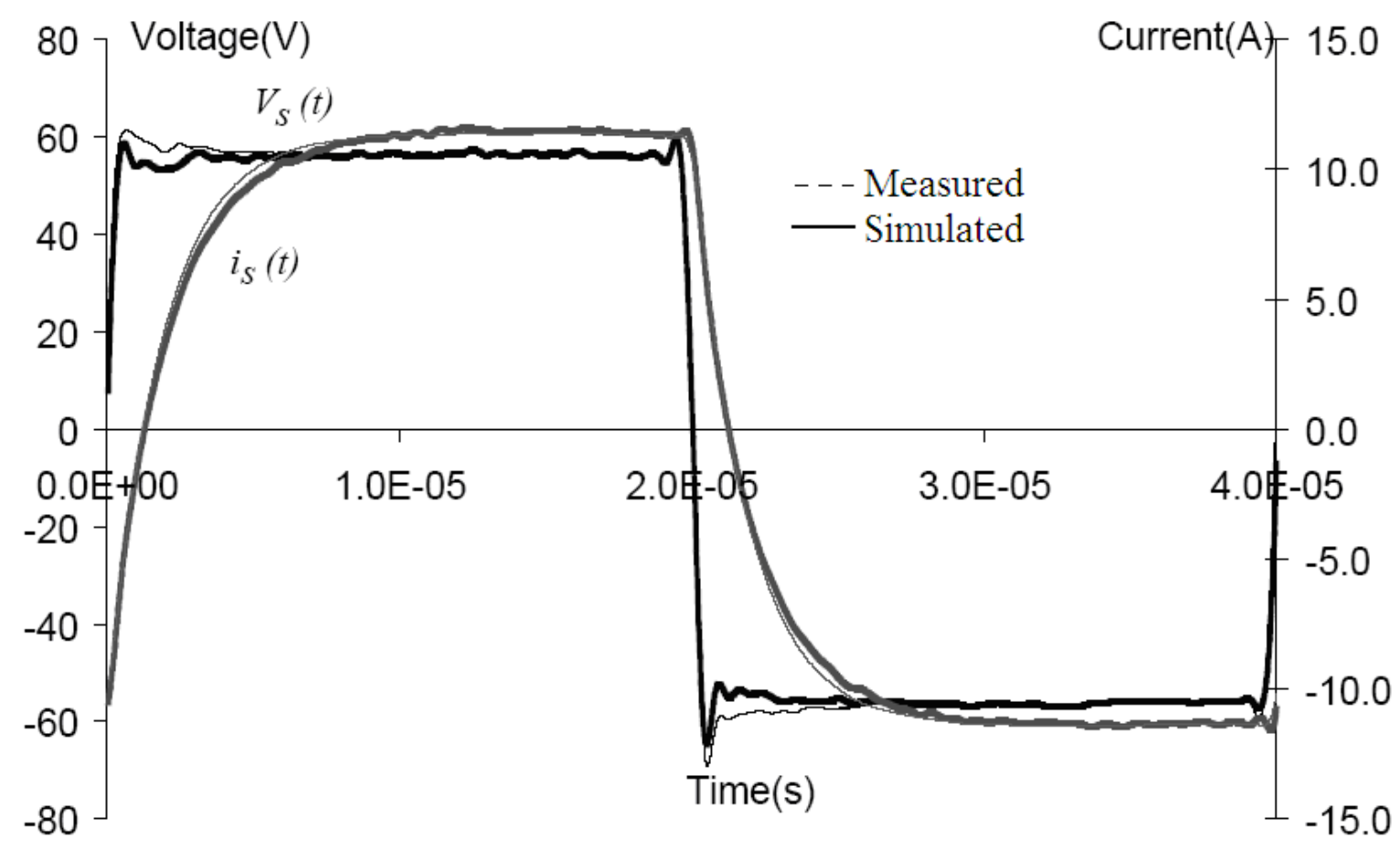

(b)

Fig. 9. Comparison of measured and simulated results by using single stray capacitor model in Fig. 3 with $C_{\text {str }}=3.70 \mathrm{nF}$ under an inductive load of $R=4.96 \Omega$ and $L=9.10 \mu \mathrm{H}$ at $25 \mathrm{kHz}$ : (a) primary current, (b) secondary current and voltage

\section{EFFECTS OF STRAY CAPACITANCE AND MAGNETIC HYSTERESIS}

\subsection{Effects of stray capacitance}

In the measured waveform of the primary current at no-load shown in Fig.6(a), there is a big dip at the instant of switching, resulting in two large reversals in the flux-excitation current loop shown in Fig.6(b), and the size of this dip decreases when the transformer is loaded as shown in Figs. 8(a) and 9(a). This is attributed to the effect of the large stray capacitances because of the foil windings used in the test transformer. Fig. 10 plots the simulated waveform of the primary current when the stray capacitances are 
ignored in the simulation model against the measured waveform. It can be seen that the stray capacitances can cause significant deformation in the primary current. However, the effect of stray capacitances has little influence on the accuracy of core loss prediction since the stray capacitors can be regarded as lossless, as shown in Fig. 11 in which the comparison of the measured and simulated flux against the excitation current loops is illustrated. It might be acceptable to ignore the stray capacitances in the proposed model when only core loss prediction is a main focus.

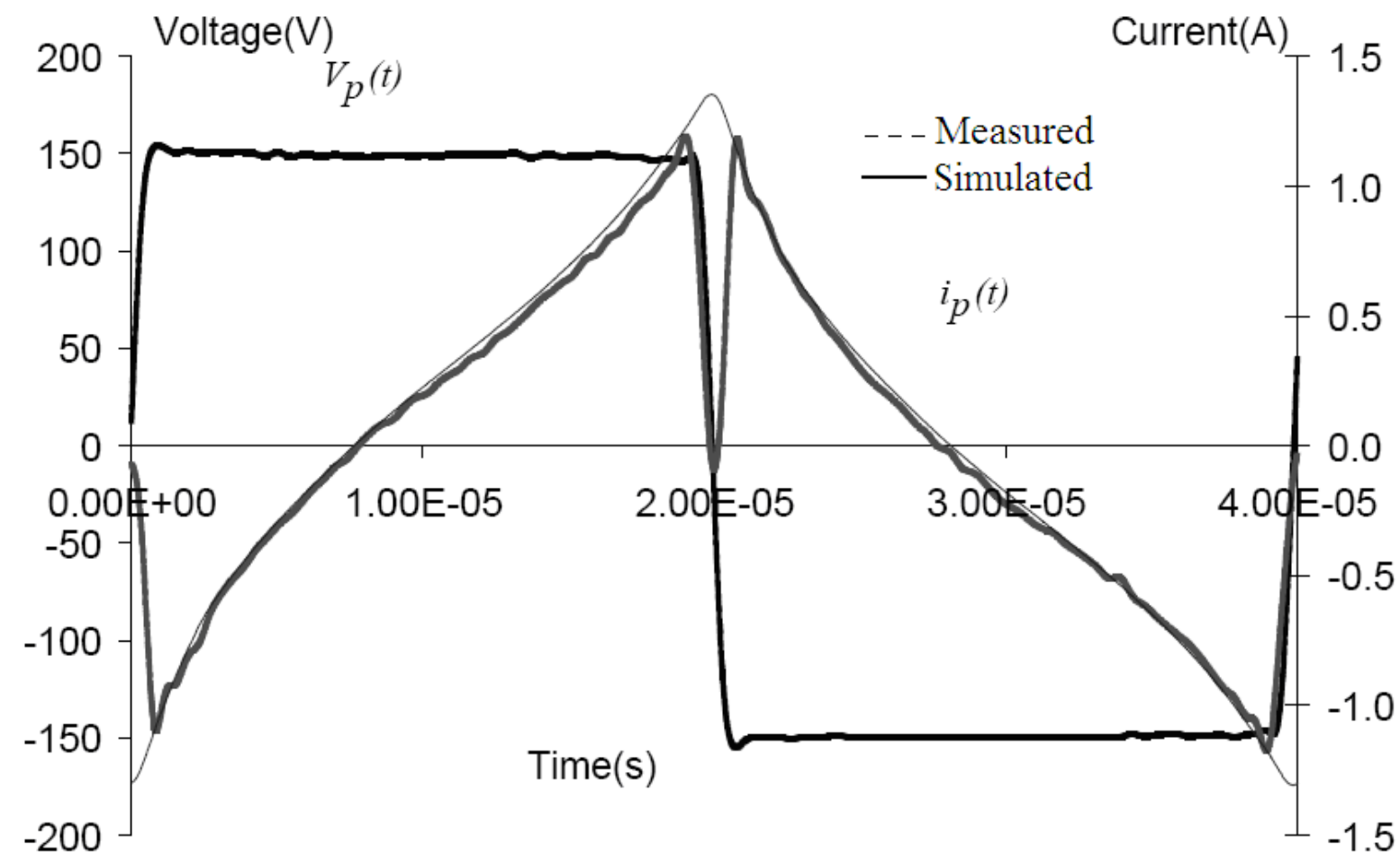

Fig. 10. Comparison of measured and simulated waveforms of primary current ignoring stray capacitances 


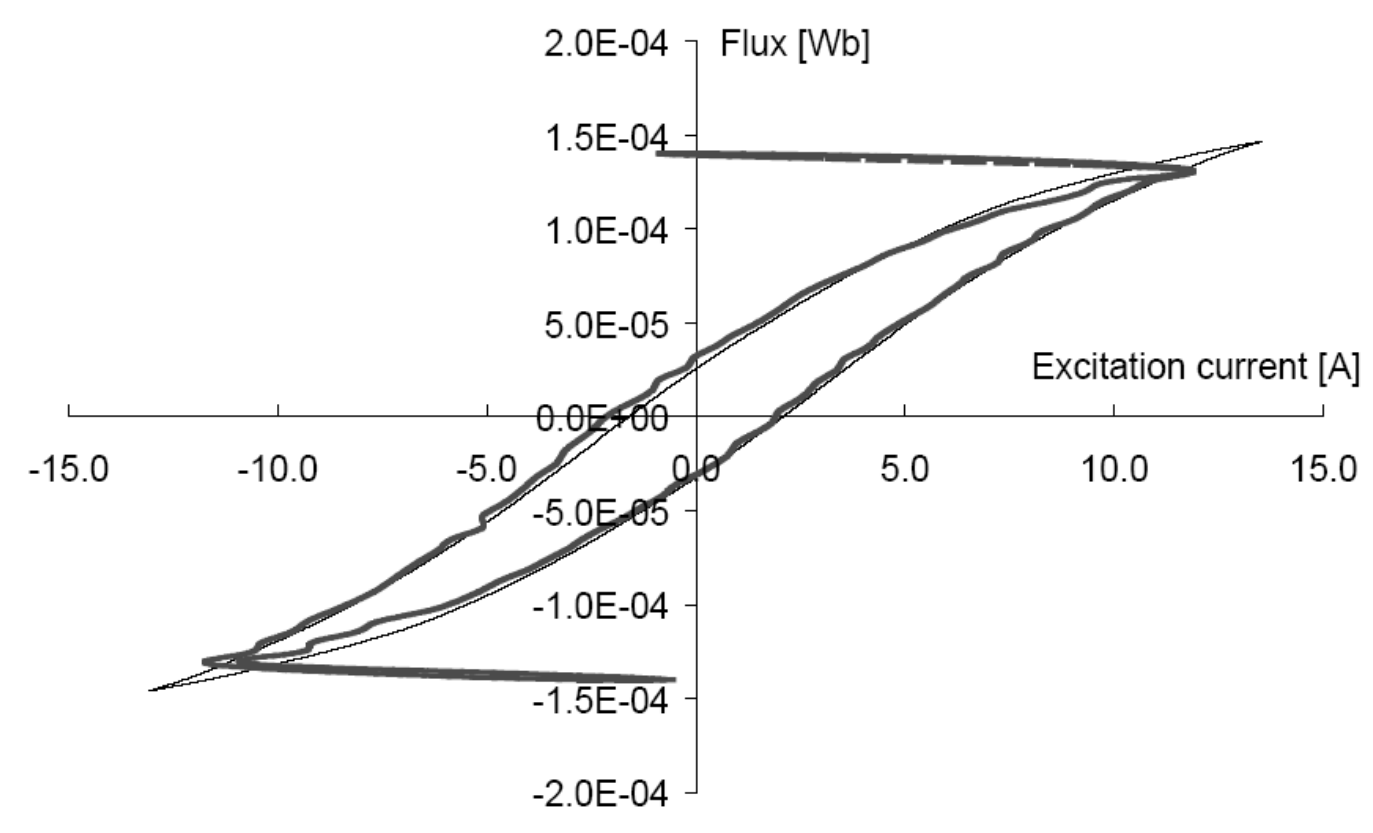

Fig. 11. Comparison of measured and simulated loops of mutual fluxes vs. excitation current ignoring stray capacitances

\subsection{Effects of hysteresis}

The hysteresis of magnetic cores has a significant influence on transformer performance. Fig. 12 plots the no load primary current predicted when the normal magnetization curve instead of the hysteresis model was used in the simulation together against the experimental results. It is shown that neglecting the hysteresis in the model of magnetic cores can cause a considerable discrepancy between the simulated and experimental results. 


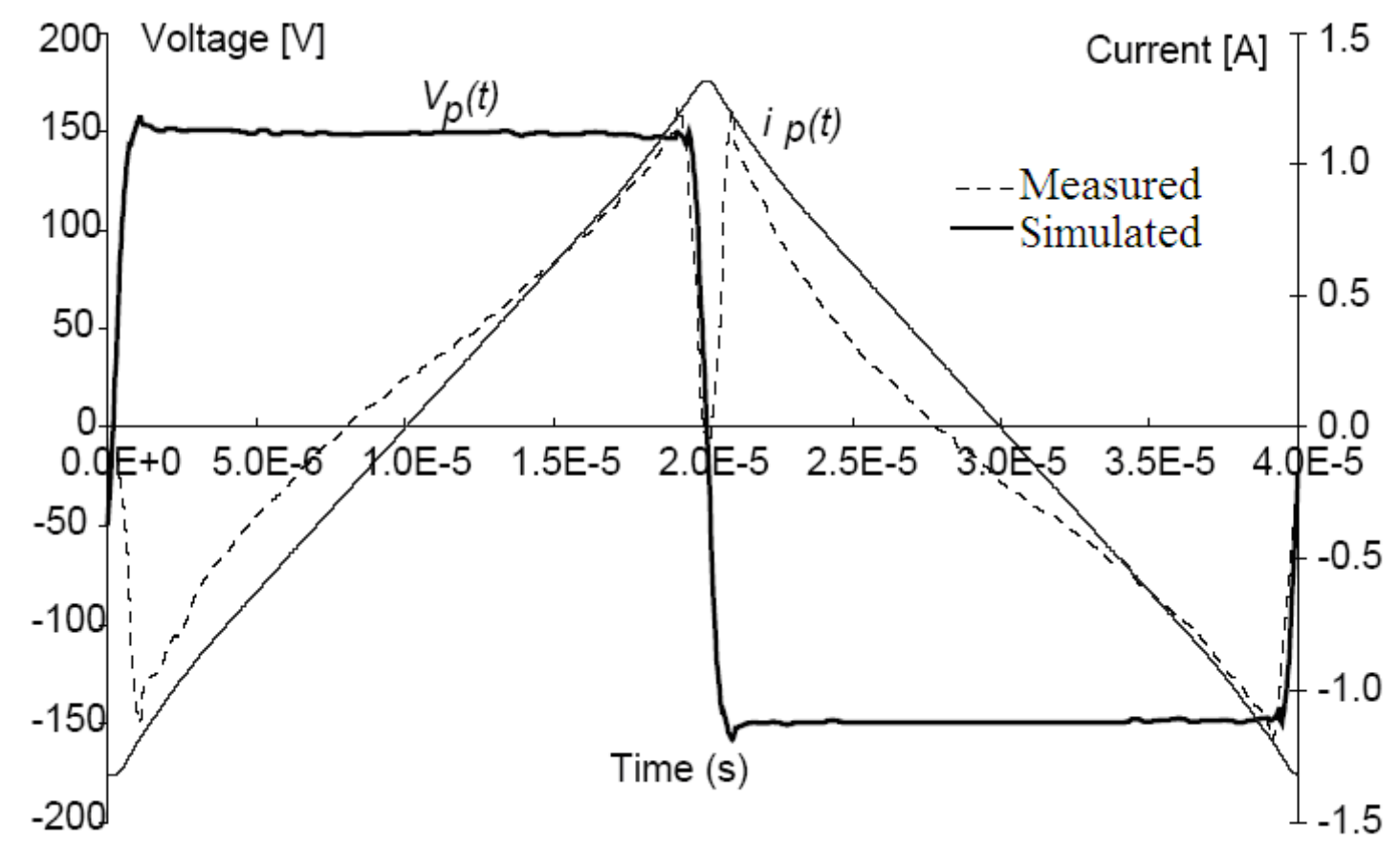

Fig. 12. Comparison of measured and simulated waveforms of primary current when hysteresis is not considered in the model

\section{CONCLUSIONS}

In conclusion, a practical circuit model and its simplified version for HFHPD transformers have been developed and confirmed by experimental measurements. The main magnetic flux in a HFHPD transformer can be modeled by the dynamic circuit of general magnetic cores. The skin effect of eddy currents in magnetic cores can be accounted for by a ladder network of non-linear resistances and non-ideal inductances. A modified scalar Preisach model of hysteresis incorporating the thermal effects is used for tracing the magnetization history and calculating the hysteresis loss. The values of leakage inductances can be determined conveniently by experimental measurement, i.e. the short circuit impedance method. The stray capacitances of HFHPD transformers can be modeled properly by a $\pi$-shaped network of three capacitors or approximately by a single capacitor across the primary terminals. The comparison between the 
simulated and measured results shows that the developed practical circuit model can truthfully predict the performance of HFHPD transformers under no-load and different load conditions. The percentage error of core loss prediction is less than $5 \%$. The ignorance of magnetic hysteresis and effects of stray capacitances could cause significant discrepancies between the simulated and experimental results.

\section{REFERENCES}

Baccigalupi A, Daponte P, Grimaldi D. On circuit theory approach to evaluate the stray capacitances of two coupled inductors. Proc. IEEE Instrument and Measurement Technology Conference, Irvine, CA, USA, 18-20 May 1993:549-553.

Blache F, Keradec J, Cogitore B. Stray capacitances of two winding transformers: Equivalent circuit, measurements, calculation and lowering. Proc. IEEE industry Applications Society Annual Meeting, Denver, USA, 2-6 Oct. 1994:1211-1217.

Grandi G, Kazimierczuk MK, Massarini A, Reggiani U. Stray capacitance of single-layer air-core inductors for high frequency applications. Proc. IEEE industry Application Society Annual Meeting, San Diego, CA, USA, 6-10 Oct. 1996:1384-1388.

Grossner NR. Transformers for Electronic Circuits. McGraw-Hill Book Company, 1967.

Hui SYR, Christopoulos C. Discrete transform technique for solving non-linear circuits and equations. IEE proceedings, Part A, Nov. 1992;139(6):321-328.

Hui SYR, Zhu JG. Magnetic hysteresis modeling and simulation using the Preisach theory and TLM technique. Proc. the $25^{\text {th }}$ Annual IEEE Power Electronic Specialist Conference, 20-24 June 1994, Taipei, Taiwan:837-842.

Hui SYR, Zhu JG, Ramsden VS. A generalised dynamic circuit model of magnetic cores for low- and high-frequency applications, Part II: Circuit model formulation and implementation. IEEE Trans. Power Electronics, Mar. 1996;11(2):251-259. 
Laveuve E, Keradec J, Bensoam M. Electrostatic of wound components: analysis results, simulation and experimental validation of the parasitic capacitance. Proc. IEEE industry Applications Society Annual Meeting, Dearborn, MI, USA, 28 Sept. - 4 Oct. 1991:1469-1475.

Lu HY, Zhu JG, Hui SYR. Experimental determination of stray capacitances in high frequency transformers. IEEE Trans. Power Electronics, Sept. 2003;18(5):1105-1112.

Lu HY, Zhu JG, Hui SYR, Ramsden VS. Dynamic circuit modeling of a high frequency transformer. Proc. the $29^{\text {th }}$ Annual IEEE Power Electronics Specialist Conference, Fukuoka, Japan, May 1998:1479-1485.

Lu HY, Zhu JG, Ramsden VS. An improved prediction of thermal effects on magnetic hysteresis of soft ferrites. Proc. Australasian Universities Power Engineering Conference, Darwin, Australia, 26-29 Sept. 1999: 382-387.

Mao XK, Chen W. More precise model for parasitic capacitances in high-frequency transformer. Proc. the $33^{\text {rd }}$ Annual IEEE Power Electronic Specialist Conference, 23-27 June 2002:1054-1057.

Massarini A, Kazimierczuk MK, Grandi G. Lumped parameter models for single- and multiple-layer inductors. Proc. the $27^{\text {th }}$ Annual IEEE Power Electronics Specialist Conference, Baveno, USA, June 1996:295-301.

Philips. Soft Ferrite Data Book 1996.

Poulichet P, Costa F, Laboure E. High-frequency modeling of a current transformer by finite-element simulation. IEEE Trans. Magn., Mar. 2003;39(2):998-1007.

SIEMENS. Ferrites and Accessories. Data Book 1990/1991.

Van Wyk JD, Lee FC. Power electronics technology at the dawn of the new millennium-status and future. Proc. the $30^{\text {th }}$ IEEE Power Electronics Specialist Conference, Charleston, South Carolina, USA, 27 June - 1 July, 1999: 3-12. 
Zhong MQ, Fung KK, Hui SYR, Christopoulos C. Improved transient simulation of circuit using variable-time step TLM technique. Proc. Int. Conf. AMSE, Oct. 1993:745-749.

Zhu JG, Hui SYR, Ramsden VS. A generalised dynamic circuit model of magnetic cores for low- and high-frequency applications, Part I: Theoretical calculation of the equivalent core loss resistance. IEEE Trans. Power Electronics, Mar. 1996; 11(2):246-250.

Zhu JG, Lu HY, Ramsden VS, Tran K. Temperature dependence of magnetic hysteresis of soft ferrites. Proc. Int. Symposium on No-linear Electromagnetic Systems, Braunschweig, Germany, 12-14 May 1997:495-498. 